\title{
Smartness, Contemplation, and Slow Research
}

\section{Robert Mitchell}

We live in a world that increasingly aspires to be smart. A smart world is in part one characterized by a growing number of smart devices - for example, smartphones, smart cities, and smart electrical grids - that link many users through sensors and real-time computation. These devices purportedly add a new kind of intelligence to both work and leisure, sometimes by blurring the distinction between those two activities. Moreover, as evidenced by the examples of smart cities and smart electrical grids, this new mode of intelligence is often presented as essential to solving otherwise overwhelming ecological dilemmas, such as human-induced climate change. The explosion of the language of smartness is thus one component of what colleagues and I have described elsewhere as a "smartness mandate": the demand that every human process become smart, so that smartness can lead us to resilient and sustainable relationships to our ecologically fragile and politically unpredictable environments (Halpern et al.).

Given the current pervasiveness of smart technologies and the smartness mandate, it is not surprising that the logic of smartness is already well-integrated into many aspects of the modern university, in both its research and teaching dimensions. I suspect that many readers of this journal have, like me, an ambivalent relationship to these processes. Many may support, for example, the digitization and algorithmicallyenabled search capacities of field-specific resources (e.g., Eighteenth-Century Collections Online), yet be less certain about, though not necessarily critical of, new "big data" humanities research methods, such as the variety of approaches often linked to Franco Moretti's call for "distant reading" practices. (And I suspect many readers share my suspicions of some of the interests served by new modes of quantitative assessment of both students and researchers, such as automated methods of grading student work and the use of "impact" metrics to assess researcher productivity).

I argue here that, in the context of the modern university, the utility and implications of smart techniques and technologies are often difficult to assess precisely because they rely on a mode of intelligence - smartness - that itself bears an ambivalent, and arguably even antagonistic, relationship to the expert model of intelligence upon which the modern university is based. This article is thus an attempt, admittedly both provisional and brief, to begin to puzzle out the relationship of the logic of smartness to the logic of the university, and to do so in a way that engages existing and future possible forms of relationships between the sciences and the humanities. I begin by summarizing briefly what my colleagues and I have described as the smartness mandate, focusing especially on four concepts central to its operation: zones, populations, optimization, and resilience. I then connect these concepts to four propositions about the university, which collectively focus attention on the contemplative, "slow" kind of intellectual work that I argue the modern university is especially suited to undertake, and on the expert model of knowledge that underwrites that contemplative model of knowledge. I conclude with a few reflections on how something like ScienceHumanities might allow those of us situated in universities to engage productively the discourse, logic, and technologies of smartness. 


\section{The Smartness Mandate}

Since my colleagues and I have described the logic of smartness at more length elsewhere, I summarize our argument here (drawing several sentences verbatim from Halpern et al.). We argue that we can understand the underlying logic of the assemblages of technologies and processes currently called smart by means of four questions, namely: 1) where does smartness happen? 2) what, exactly, is smart? 3) what does smartness $d o$ ? and 4) what is the goal, or telos, of smartness?

1. Smartness happens through zones. Smartness never happens in one place, but emerges across networks, as multiple places are linked in multiple ways. My iPhone is smarter than my old rotary telephone not just because it frees me from cords and local networks, but because it simultaneously links me to newsfeeds, maps, and Facebook. Moreover, though it relies on a national telephone carrier, it links that restricted network to a multitude of carriers and networks in other countries. This interweaving of national and global spaces exemplifies the logic of zones. Whether it is the Zone of Thomas Pynchon's Gravity's Rainbow, the zones of indistinction theorized by philosopher Giorgio Agamben, or free trade zones, contemporary zones are now almost always spaces of exception; that is, spaces in which at least two sets of otherwise incompatible rules are folded into one another. For example, as Keller Easterling has noted, free trade zones combine the territorial logic of the national state with the globalized logic of commodity flows, for though the free trade zone is located within a national territory, it is exempted from many national laws in order to facilitate global trade.

Smartness depends upon zones in two ways. First, smartness relies on the zonal logic of existing global communication and logistical systems, such as satellite systems and optical fiber infrastructures. I can use my smartphone to update my Facebook page while traveling in another country only if the infrastructures and networks upon which my phone relies are protected by the territorial laws and security forces of multiple national states. At the same time, the global work of data analysis and linkage upon which my smartphone and Facebook rely functions only if these processes are partially exempted from the narrowly national interests served by these legislative and security regimes. Second, smart technologies and smart milieux, such as smartphones and smart cities, serve to normalize the logic of the zone. While many of our contemporary economic activities rely on free trade zones, the fact that free trade zones are discrete, small, and geographically-restricted sites suggests, by implication, that zones constitute a small number of exceptions to the normal operations of territorial space. Smart technologies such as a smartphone, by contrast, each function as their own mini-zones, encouraging in us the paradoxical sense that zones and their spaces of exception are in fact the normal and dominant forms of space and relation.

2. The subject of smartness is the population. Just as smartness does not happen in one place, it is also not an activity that occurs in specific individuals or technologies. In a smart electrical grid, neither the grid itself, nor the individuals who use it, are themselves smart in the sense intended by the phrase smart grid. Rather, smartness characterizes the entire population of individuals connected by the grid. That is, the smartness of the electrical grid emerges when the population of energy users is connected by means of the grid's specific algorithmically-assisted operations.

There are two key premises of this concept of population implicit in the notion of smartness. First, rather than understanding a population as a homogeneous collective mass (in the style of, say, concerns about a Malthusian population explosion), smart technologies and processes generally focus on ways in which members of a population differ from one another with respect to desires, capacities, income, spending preferences, or other variables. A smart electrical grid, for example, purportedly enables 
more efficient, greener uses of power by algorithmically leveraging differences in, for example, energy use and location among different users of the grid. From this perspective, each member of the population is in fact "dumb," in the sense that each individual has only his or her limited perspective, preference, and locale. The computer technologies and algorithms that link members of a population through smart technologies are also dumb. However, the second premise that smartness makes about populations is that, by linking these multiple limited perspectives, computer technologies and algorithms can bring into being a form of collective intelligence namely, smartness - that can emerge only at the level of the population.

3. Smartness optimizes. When a smart technology employs zonal logic to connect the limited perspectives, preferences, or capacities of individuals in a population, what justifies calling this smartness is the key operation of the latter: namely, optimization. Optimization is a quantitative operation of locating limits (maxima and minima), such as the Google Map problem of finding the shortest path that connects several locations within a city. The optimization problems engaged by smartness are also generally calculation-intensive, requiring millions or billions of algorithmic mathematical calculations. Hence the important role of computers (which can churn through complex algorithms at speeds effectively real-time for humans), globally distributed sensors (which enable constant global updating of information), and global communications networks (which connect those sensors with that computing power).

Optimization is an old technique, but the smartness mandate presumes that everything - every kind of relationship among humans, their technologies, and the environment in which they live - can be optimized. Shopping, dating, exercising, the practice of science, the distribution of resources for public schools, the fight against terrorism: all of these processes can - must! - be optimized. Optimization fever propels the demand for ever more sensors - more sites of data collection, whether via mobile device apps or hospital clinic databases - so that optimization's realm can perpetually be expanded, and optimization itself further optimized.

4. Smartness aims to produce resilience. Optimization may seem like an end in itself, in the sense that it is hard to imagine preferring processes that are less efficient, or slower, or weaker. Yet comparatives and superlatives (faster and fastest; stronger and strongest) cannot be ends in themselves, but rather have value only in reference to a final end, or telos. The end toward which smartness aims is resilience. Resilience is a key term in many contemporary fields, from engineering to social psychology to public policy. In each, it means an ability to withstand and absorb shock. This is also the key to the ecological concept of resilience, from which the discourse of smartness draws most heavily. In the 1970s, ecologist C. S. Holling distinguished between ecological stability and resilience (14). Holling noted that ecologists and policy makers generally assumed that ecological systems were healthiest when they were stable; that is, could regain equilibrium after perturbations. Yet Holling argued that the stability of ecological systems often rendered them unable to deal with truly anomalous events (18). Resilient ecosystems, by contrast, changed in the face of unexpected events rather than returning to equilibrium, and thus persisted in conditions in which stable ecosystems collapsed.

Smartness extends this originally ecological concept of resilience, suggesting that the second nature produced by smartness - the environment of sensors, networks, computational capacity, and optimization - enables humans to remain in relationships of persisting resilience with both ecological and political shocks and perturbations. Yet because resilience assumes a world in which anomalous events are the norm, so to 
speak, the discourse of smartness subtly encourages us to understand our situation as a state of perpetual instability which can only be addressed by resilient techniques and structures.

\section{Four Propositions on the University}

As I noted at the start of this article, smart technologies have often emerged from, and are swiftly being incorporated into, many universities. Google's search engine (and company) is an example of the former process, for the original version of its search engine - PageRank - was developed in the Stanford University InfoLab and was explicitly based on the citation index system employed by scientific researchers (Page et al.; see also Pasquinelli). Examples of smart technologies moving into the university include the now ubiquitous (if not always condoned) use of smartphones and tablets in university classrooms and faculty and committee meetings, and the crowd-sourced encyclopedia Wikipedia, which was developed largely outside the university, but is now employed - albeit also often ambivalently - by many university researchers and students. There are, however, several fundamental tensions between the logic of smartness and the logic of the modern university. These tensions can be illuminated by means of four propositions about the modern research university. ${ }^{1}$

Proposition 1: The modern university is oriented toward slow research. A key characteristic of the modern research university that distinguishes it from other contemporary knowledge-producing institutions, such as corporations, think tanks, and government bodies, is its investment in a slow mode of research. The modern research university is not designed to answer topical questions quickly, but is rather structured to enable a patient, thorough approach to so-called basic research questions (i.e., questions that often seem to respond more to the demands of curiosity or long-term knowledge accumulation than to pressing short-term concerns). This orientation toward slow research is evident in multiple aspects of the university, including the long $\mathrm{PhD}$ training (generally at least 5 years in the United States) and pre-tenure probationary periods (generally 5-6 years in the United States) required of those who conduct university research and teaching. Though a slow mode of research characterizes both the sciences and the humanities, slowness is especially evident in the publication review and production processes of the humanities, which can take up to 2-3 years for articles and books. Yet in the university sciences too, research is understood as something that is better done thoroughly than quickly, and with an eye to basic questions that may have no immediate practical applications. And though university researchers in the sciences must often coordinate their results with government grant funding periods, this is quite different from the process of coordinating results with the product cycles that characterize corporate science funding. The result is a mode of research that can be, at least from the perspective of policy makers and members of the public, quite slow and only partially responsive to current pressing problems.

Proposition 2: Slow research tends to produce knowledge in excess of demand. In part because of its slow mode of research, the modern university, as Stefan Collini has noted, tends to produce knowledge in excess of what its current funders want (7-8). Universities are largely funded by governments or wealthy donors (or both), and these funders always have some sense of what they want in exchange for financial resources. However, because of their slow and relatively protected modes of researching, universities seem invariably to produce more knowledge, and often different kinds of knowledge, than that explicitly requested by their funders. Depending on the perspective of those funders, this excess can either be seen as the necessary cost of 
progress in desired funding areas, or (increasingly) as a waste of funding and researcher attention.

Proposition 3: The modern university is a site of mediation between the vita activa and the vita contemplativa. Likely because it operates in such an untimely fashion, the modern university, especially the public university, has been a key site of negotiation of collective aspirations for both the vita contemplativa and what Hannah Arendt called the vita activa (see The Human Condition and The Life of the Mind). That is, twentieth- and twenty-first century discussions about the proper structure, funding, and student composition of the university are, often and perhaps invariably, fundamentally debates about how to balance two images of life. On the one hand is an image of life as best lived when one retreats from the world of politics and earthly interests to focus solely on the life of the mind. On the other hand is an image of life as best lived when individuals engage in agonistic debate with others about collective directions, with resulting concrete actions that resolve current problems. My claim is not that the modern university judges, disjunctively, which of these two forms of life is better, but rather that the university is an institution in which administrators, professors, and students seek to balance these two forms of life. Efforts to balance these two forms of life are, I suggest, at the heart of debates about which modes of research (and, sometimes, departments) belong within the university; the relationship of professional schools to the arts and sciences dimension of the university; how student enrollment should relate both to general demographical trends and to historical and current forms of injustice and inequity; and which methods should be used to assess the impact of university research on society as a whole. The university is the site of these balancing acts in large part because it is an institution that, either through its public funding or non-profit tax status, is understood by the wider public as a key medium within which collective values are put into concrete practice.

Proposition 4: The modern research university engages two opposed concepts of population. In the modern research university, both reflections on the most appropriate forms of research and on how to balance the vita contemplativa with the vita activa have implicitly engaged two quite different concepts of population. On the one hand, the modern university has generally been understood, in both its teaching and research dimensions, as an institution that houses the best of a regional, national, or even global population. On the research side, for example, departments seek to hire the best researchers and instructors by means of rigorous credentialing and selection procedures, while on the teaching side, universities seek the best undergraduate and graduate students by means of test scores and other aspects of candidates' applications. On the other hand, higher education has been described frequently in recent decades as an economic necessity - and even quasi-right - for the vast majority of the population, both via the very concrete claim that only a university education allows individuals to get ahead financially, and in the more aspirational sense that the experience of higher learning should not be restricted to a self-reproducing elite (Newfield).

There are fundamental tensions, perhaps even contradictions, between these two population approaches of the university. Most obviously, a university degree allows an individual student to get ahead - which means, to secure employment in an otherwise uncertain labour market - only if the university remains exclusive. That is, possession of a university degree differentiates one individual from another for employers only when the university is understood as selecting solely the small best subportion of the more general population. However, just as the university does not decide between the vita contemplativa and the vita activa, but is rather the site of continuous efforts to balance these two aspirations, the university is also a site in which the exclusive and 
inclusive senses of population - the sense of the university as a place where the best of a population is gathered, and the sense of the university as an organization of knowledge-production that ought to be accessible to everyone - are brought into connection with one another.

\section{Universities, Smartness, and Markets}

None of these four aspects identified by my propositions are, of course, essential to the university, or even the modern research university. Western universities have been oriented toward slow research since their origins in the medieval period, and have since then often produced knowledge in excess of what those paying the bills have hoped for. Yet the university has mediated relationships between the vita contemplativa and the vita activa arguably only since the early nineteenth century, following its Humboldtian reconfiguration, and the tension between exclusive and inclusive understandings of population has been relevant for the university only since roughly the 1950s. Moreover, some existing institutions call themselves universities yet lack some or all of the characteristics noted above. In addition, many recent university administrative initiatives - including excitement for translational research over what used to be called basic research; increasing interest in the United States in eliminating tenure; and the embrace of a consumer model of the university student - all seem, whether intentionally or not, to undercut one or more of the characteristics of the university I outlined above. With that said, though, my sense is that my four propositions nevertheless accurately describe most universities as they exist now, and (I hope) as they are likely to exist at least for another decade.

These four propositions help bring into view several tensions between the logic of the modern research university and the logic of smartness. The first, and most basic, of these tensions revolves around their opposed models of knowledge. Whereas the university presumes that knowledge is produced within small expert communities, smartness presumes that intelligence occurs only when the distributed, limited perspectives of entire populations are mediated algorithmically. This conflict is at the heart of several debates within universities, including debates about the acceptability of citing the collectively-generated Wikipedia in undergraduate papers and scholarship (see Tkacz); the efficacy of expert versus crowdsourced or automated methods of grading student work (see the admittedly critical resources gathered at "Human Readers: Professionals Against Machine Scoring of Student Essays In High-Stakes Assessment", humanreaders.org/petition/research_findings.htm); the utility and goals of the flipped lecture class, which generally reconfigures the classroom itself from the meeting point of experts and novices to the site of collaborative groupwork; and the goals of Massive Open Online Courses (MOOCS), which often employ the model of an expert who disseminates knowledge, but also often rely on either algorithmic or crowdsourced assessment techniques (see Losh).

While advocates of these new technologies and strategies presumably often hope to mediate between the university and smartness by locating points of connection and articulation between two otherwise opposed logics, these strategies can also easily facilitate neoliberal efforts to reconfigure the university as simply another market provider of services. There is significant resonance between the logic of smartness and the neoliberal understanding of the market as a decentralized information processor which, through its price system, coordinates the limited perspectives of the individuals more efficiently than other conceivable processes. Or, as Friedrich Hayek put it, "[t]he whole acts as one market, not because any of its members survey the whole field, but because their limited individual fields of vision sufficiently overlap so that through 
many intermediaries the relevant information is communicated to all" (256) (see also Mirowski and Plehwe, Mirowski, Science-Mart, and Mirowski, Serious Crisis). Neoliberals see no reason to exempt the university from this vision of the market as smartness avant la lettre. They thus favour developments that contain the excess of university knowledge, that undercut attempts to mediate between the vita contemplativa and the vita activa, and which cast doubt on the image of the university as a gathering of expert communities, since none of these are compatible with the image of a marketoriented service provider. ${ }^{2}$ This neoliberal vision of the university as a market-oriented service provider is encouraged, whether intentionally or not, by new techniques that undercut the premise of expertise, such as crowdsourced and machine assessment of student work and automated peer review of faculty research papers. My point is not that such techniques should for that reason be rejected, but rather that the relationship of such techniques to expert communities should be central to discussions of these techniques.

Though the logic of smartness is distinct from the neoliberal vision of market intelligence, two tendencies inherent in the logic of smartness make it difficult to keep these distinctions in view, especially as they relate to the university. First, just as neoliberals argue that market intelligence is really the only true kind of intelligence (since only the market can transform otherwise dispersed individual perspectives into collective intelligence), the language of smartness also tends to eliminate discussion of the proper balance between the vita contemplativa and the vita activa by appealing to a new mode of intelligence (smartness) that purportedly encompasses both. The concepts of contemplation and basic research depend upon images of individual thinkers and expert communities. However, smartness is a mode of intelligence that, because of its reliance on distributed populations and technological (generally algorithmic) mediation, cannot be fully instantiated in any individual human's thought, or even in the thought of an expert research community. For the same reason, smartness dispenses with that conscious engagement with the social world that Arendt called action, and which we in the humanities have tended to call critique. In place of the individual perspectives that necessarily inform action and critique, smartness substitutes a neverending process of population-based optimization. Smartness claims to assimilate critique, for perpetual optimization requires perpetual dissatisfaction with the present, and the premise that things can always be better. Yet this commitment to a formal process of never-ending optimization makes smartness itself difficult to critique, especially since its advocates will happily seek to readdress any inequities in its current instantiations - for example, the digital divide, the working conditions of the people who assemble smart phones, or the environmental costs of smart technologies - in the next version of the smart world. Smartness thus potentially displaces, by claiming to optimize, scholarly aspirations for both contemplation and critique.

The increasing ubiquity of implementations of smart technologies in our daily lives also makes smartness difficult to critique. Even as some of the developments I have outlined above may trouble us, these concerns are partially negated by our equally deep commitment to the forms of algorithmic optimization operative in our daily experience with, for example, smartphones and search engines. My point is not that such experience obscures one critical truth (that smartness is problematic), but rather that it establishes another truth: namely, that there are indeed realms in which population-based, algorithmic-assisted calculation produces results more swifly, or produces results more valuable, than those that would have been rendered either by individual judgment or the professional judgment of field experts. Predictably, smartness's advocates within universities often seek to plot these two truths within a 
chronology of progress, contending that though the expert model of knowledge may have been necessary during the medieval origins of the university, recent technological advances now allow us to dispense with that anachronistic model as we create the university of the future. However, in the final section of this article, I hope to work against this questionable progress narrative by considering ways in which we might help structure the university of the future by balancing, rather than deciding between, these two truths about smartness. As I note below, this balancing act will likely be most successful if it involves linking the sciences and the humanities, rather than - as is sometimes the case in advocacy of STEM (science, technology, engineering, and mathematics) approaches - emplotting the humanities as either part of the anachronistic past of the university or as a merely optional supplement to the sciences.

\section{Smartness, Slowness, and ScienceHumanities}

I want to stress that my account of the relationship between smartness and the modern university does not aim to protect the latter from the former. It is far too late for such prophylactic measures, and such a critique would be hard pressed to overturn the experiential proofs of the efficacy of smartness provided by our daily immersion in its technologies. Instead, I hope that, by articulating the logics of smartness and the modern research university into their component parts and aspirations, we can think more effectively about how to bring together tools from the humanities and the sciences in ways that allow smart techniques and technologies to support the aspects of the modern university that I outlined above in my four propositions. This step would in turn underscore the important differences between smartness and neoliberal market intelligence.

One (perhaps obvious) strategy is to use public-facing aspects of universities, such as websites, to facilitate technical literacy around some of the basic techniques and concepts of smartness (e.g., Bayesian reasoning, evolutionary optimization algorithms, and resilience). Some of this work will likely be critical in the traditional sense of illuminating the assumptions embedded in these techniques, and identifying which groups benefit from these assumptions and techniques. Ideally, though, such technical literacy would also enable members of publics reached by such education to use these techniques and concepts for their own purposes, and thereby begin to refashion the key concepts of smartness (zones, populations, optimization, resilience).

It also seems important to begin mapping and more fully articulating the different implicit models that justify the connection of smartness to populations, in part so that we can begin to make distinctions between arguably opposed concepts of collective intelligence. Though there are family resemblances among contemporary concepts of, say, swarms, crowdsourcing, collective intelligence, spontaneous order, and multitudes, there are also significant differences among the premises of these terms. For example, a model of collective intelligence in which one requires a large population in order to select those few who can excel at something (what we might call the American Idol or X Factor model) is more or less completely opposed in aspiration and assumptions to a model that presumes that collective intelligence requires the contribution of each individual in a population (e.g., Pierre Lévy's collective intelligence model). As I note above, the highly competitive admission and employment methods of modern universities unarguably employ a selective model of population. However, explicit reflection on different models of the relationship between populations, institutions, and intelligence would likely allow universities, especially public universities, to amplify their simultaneous commitment to more inclusive models of collective intelligence. 
It also seems worth theorizing more thoroughly, and describing more explicitly and publicly, the relationship between the necessarily historical dimension of much humanities research and the equally justifiable ahistorical approach of most sciences. As commentators as varied as Thomas Kuhn and Gilles Deleuze and Félix Guattari have noted, cutting edge work in a science such as physics does not require that its current practitioners have much, or any, grasp of the history of physics (Kuhn 167; Deleuze and Guattari 124-5). Humanities disciplines, by contrast, invariably have a strong historical dimension or subfield, and require their researchers to understand the history of their discipline. The premise of this historical dimension, I suggest, is that humanities disciplines assume that they are responsible for maintaining, analyzing, and continuing a long, distributed, and decentralized conversation that takes place over multiple generations and populations. This conversation among radically different groups and times can occur only if past voices are encountered as past voices; hence, the importance of primary texts / objects for many humanities disciplines. In addition, the specific ways in which the past can bear upon the present and the future are difficult or impossible to specify in advance; hence, the importance of individual perspectives of humanities researchers over generic methods. The humanities presume, in short, that it is vital to maintain a memory of as many past and present forms of human collective life as possible, both for the sake of helping us to understand contemporary and future problems, and as an end in itself. This historical dimension of the humanities does not put it in conflict with the ahistorical tendencies of the sciences, but rather underscores that the sciences and the humanities aim at different ends, and presumably each works best when each is informed by the other.

Understanding the humanities as maintaining, analyzing, and continuing a long, distributed, and decentralized conversation is another, arguably more positive, way of describing the slowness of humanities research. I find the concept of slowness useful in part because it works against the presentism that has found so much recent favor among university administrations, especially in the form of buzzwords such as innovation, cutting edge, and translational. Yet one danger of the concept of slow research is that it may be seen as simply a variant of contemporary forms of consumer-oriented slowness, such as the slow food movement, which function only via the support of largely invisible service laborers (Sharma 108-135). The slowness of university research is, from my perspective - as well, presumably, from the perspective of academic researchers who critique these other forms of slowness - different in kind from consumer-oriented slowness, and instead more in the mode of the "untimeliness" that Lutz Koepnick describes in On Slowness (5-6). Connecting the concept of slow research with the concept of a long, distributed, and decentralized conversation among various past and present populations of humans (and perhaps even non-humans) is one way of stressing this difference.

As underscored by both my discussion of the concept of smartness and by several contributions to this special issue (for example, those of Clifford, Otter, Smith, and Cordle), environmental and ecological concerns constitute especially productive sites for connecting the slow humanities with the sciences. This is in part because the global interconnections that are the subject of environmental and ecological scientific approaches tend to lead us not only to questions of the long-term consequences of collective human actions on environmental and ecological systems, but also to the values that are, or are not, enabled by these long-term consequences. Such values are implicit even in a concept as apparently value-averse as resilience, since it is generally presumed that resilience relies on the stability of at least some aspects of contemporary society, such as globalized, consumer-oriented trade and all of the political, security, 
and infrastructural instititions that enable this trade. Clifford's, Otter's, Smith's, and Cordle's contributions to this volume emphasize the wide variety of humanities and science disciplines, ranging from physical anthropology to philosophy to urban history and literary studies (to name just a few of the disciplines employed in these articles) which can, and arguably must, inform reflections on the relationship of human actions to global environmental and ecological systems.

I would encourage advocates of ScienceHumanities, and especially those who are advocates of the current form of the university, to understand smartness and its technological implementations as a means for balancing the ends of the vita contemplativa and the vita activa. Part of what makes smartness so difficult to grasp is its near-elimination of the question of ultimate ends or values. Smartness and its key operation, optimization, are in principle simply means for achieving another end, namely, a resilient human population. Yet, as I note above, resilience is often understood not as a specific, concrete state or set of values, but rather a mode of perpetual flexibility. As a consequence, remaining smart may seem to mean, in essence, avoiding any stable value commitments. However, as I have also noted above, the contemporary university aims neither at optimization nor resilience, but rather aims to facilitate slow, excessive modes of research that support both the vita contemplativa and the vita activa. Though smartness per se aspires to neither of these concepts of life, its techniques can, presumably, be oriented toward these values of contemplation and action, and we can facilitate this work by underscoring the importance and diversity of these forms of life (contemplation and action) for past and present human communities. This will, of necessity, be a cross- and multi-disciplinary endeavor - a project of ScienceHumanities - in multiple senses. The humanities should no doubt continue to serve a critical function in the face of often myopically presentist uses of the sciences. However, the humanities can also serve as a form of long-term memory of human institutions and possibilities that in turn informs - and, one hopes, sometimes reconfigures - contemporary research paradigms that draw their primary orientation from the sciences. 


\section{Notes}

1. My second proposition is cribbed from Stefan Collini's What Are Universities For?, and each of my propositions has benefitted from Collini's book. Though I am especially concerned with the shifting role of the humanities in universities, I agree with Collini that these changes can only be understood by focusing on the more general context of the university. Other books important for my account of smartness and the university include Ginsberg's The Fall of the Faculty, Newfield's Unmaking the Public University, and Mirowski's Science-Mart.

2. Historian of economics Edward Nik-Khah notes that neoliberal economists such as George Stigler have been candid about their desire to reconfigure completely university science, which Stigler saw, in Nik-Khah's words, as "incapable of selfregulation." For Stigler, "[a] market-governed science would dispense with elements of academic freedom to preserve intellectual freedom. It would utilize contract research and be conducted outside the structure of academic departments, under close supervision of one empowered to deliver on promises made to patrons" (Nik-Khah, "What Is 'Freedom' in the Marketplace of Ideas?" 67). 


\section{Works Cited}

Arendt, Hannah. The Human Condition. 2nd ed., U of Chicago P, 1998.

---. The Life of the Mind. Harcourt Brace Jovanovich, 1978.

Collini, Stefan. What Are Universities For? Penguin, 2012.

Deleuze, Gilles and Félix Guattari. What Is Philosophy? Translated by Hugh Tomlinson and Graham Burchell, Columbia UP, 1994.

Easterling, Keller. "Zone: The Spatial Softwares of Extrastatecraft." Places, 2012, placesjournal.org/article/zone-the-spatial-softwares-of-extrastatecraft/.

Accessed 11 Dec. 2017.

Ginsberg, Benjamin. The Fall of the Faculty: The Rise of the All-Administrative University and Why It Matters. Oxford UP, 2011.

Halpern, Orit et al. "The Smartness Mandate: Notes toward a Critique." Grey Room, vol. 68, Summer 2017, pp. 106-129.

Hayek, Friedrich A. von. "The Use of Knowledge in Society." American Economic Review, vol. XXXV, no. 4, 1945, pp. 519-530.

Holling, C. S. "Resilience and Stability of Ecological Systems." Annual Review of Ecological Systems, vol. 4, 1973, pp. 1-23.

Koepnick, Lutz P. On Slowness: Toward an Aesthetic of the Contemporary. Columbia UP, 2014.

Kuhn, Thomas S. The Structure of Scientific Revolutions. 3rd ed., U of Chicago P, 1996.

Lévy, Pierre. Collective Intelligence: Mankind's Emerging World in Cyberspace. Translated by Robert Bononno, Perseus Books, 1997.

Losh, Elizabeth, editor. MOOCs and Their Afterlives: Experiments in Scale and Access in Higher Education. U of Chicago P, 2017.

Mirowski, Philip. Never Let a Serious Crisis Go to Waste: How Neoliberalism Survived the Financial Meltdown. Verso, 2014.

---. Science-Mart: Privatizing American Science. Harvard UP, 2011.

Mirowski, Philip and Dieter Plehwe, editors. The Road from Mont Pèlerin: The Making of the Neoliberal Thought Collective. Harvard UP, 2009.

Moretti, Franco. Distant Reading. Verso, 2013.

Newfield, Christopher. Unmaking the Public University: The Forty-Year Assault on the Middle Class. Harvard UP, 2008.

Nik-Khah, Edward. 'What Is 'Freedom' in the Marketplace of Ideas?" Neoliberalism and the Crisis of Public Institutions. Working Papers in the Human Rights and Public Life Program, edited by Anna Yeatman, vol. 2, Western Sydney University, 2015, pp. 56-69.

Page, Lawrence, et al. "The Pagerank Citation Ranking: Bringing Order to the Web." Technical Report, Stanford InfoLab, Stanford University, 1999. http:/ilpubs.stanford.edu:8090/422/.

Pasquinelli, Matteo. "Google's Pagerank Algorithm: A Diagram of the Cognitive Capitalism and the Rentier of the Common Intellect." Deep Search: The Politics of Search Beyond Google, edited by Konrad Becker and Felix Stalder, Transaction Publishers, 2009, pp. 152-162. Also available at: matteopasquinelli.com/google-pagerank-algorithm/. Accessed 11 Dec. 2017.

Sharma, Sarah. In the Meantime: Temporality and Cultural Politics. Duke UP, 2014.

Tkacz, Nathaniel. Wikipedia and the Politics of Openness. U of Chicago P, 2014. 